\title{
OS JURISTAS SABEM DO QUE ESTÃO FALANDO OU FALAM SOBRE O QUE SABEM? UM DIÁLOGO ENTRE ARGUMENTAÇÃO JURÍDICA E HERMENÊUTICA FILOSÓFICẢ
}

\section{DO JURISTS KNOW WHAT THEY ARE TALKING ABOUT OR TALK ABOUT WHAT THEY KNOW? A DIALOGUE BETWEEN LEGAL ARGUMENTATION AND PHILOSOPHICAL HERMENEUTICS}

\author{
${ }^{1}$ Vanessa Nunes Kaut \\ ${ }^{2}$ Vitor Amaral Medrado
}

\section{Resumo}

Apesar de mais populares no âmbito jurídico, as teorias da argumentação jurídica não respondem satisfatoriamente à questão: os juristas sabem do que estão falando ou falam sobre o que sabem?, ou, em termos mais específicos, à pergunta: qual é o papel do conhecimento na construção da interpretação? Isso porque parece faltar em tais teorias uma visão crítica sobre a interpretação como processo de compreensão e de sua importância no processo decisório. Por outro lado, perguntas dessa abrangência podem ser enfrentadas a partir da propedêutica oferecida por uma teoria do conhecimento, que deve, então, ser parte constituinte das teorias contemporâneas da interpretação. Portanto, ao contrário da tendência recente na Filosofia do Direito de limitar a interpretação às teorias da argumentação jurídica, reportamos não ser possível uma teoria abrangente da interpretação jurídica sem uma reflexão a priori sobre o processo de compreensão, a exemplo daquelas oferecidas por Heidegger e Gadamer. No mesmo sentido, também é problemático limitar a discussão sobre a prática da interpretação à hermenêutica filosófica, como sugere Streck. Se estivermos certos, será possível vislumbrar que as teorias da argumentação jurídica e a hermenêutica filosófica devem ser entendidas, antes, em sua complementariedade, do que em suas diferenças.

Palavras-chave: Interpretação, Argumentação jurídica, Hermenêutica filosófica, Teoria do conhecimento

\footnotetext{
${ }^{1}$ Professora na Pontifícia Universidade Católica de Minas Gerais (PUC/MINAS), Minas Gerais (Brasil). Mestrado em Direito pela Pontificia Universidade Católica de Minas Gerais (PUC/MINAS), Minas Gerais (Brasil). Email: vanessakaut@gmail.com

${ }^{2}$ Professor na Universidade Católica de Minas Gerais,(PUC/MINAS), Minas Gerais (Brasil). Doutorando em Direito pela Pontifícia Universidade Católica de Minas Gerais (PUC/MINAS), Minas Gerais (Brasil). Email: vitormedrado@live.com
} 


\begin{abstract}
Although more popular in the legal framework, theories of legal argumentation does not satisfactorily answer the question: do jurists know what they are talking about or talk about what they know?, or, more specifically, to the question: what is the role of knowledge in the building of interpretation? It seems to be lacking in such theories a critical view of the interpretation as a process of comprehension and its importance in the decision making process. On the other hand, questions of this scope can be addressed from the propaedeutics offered by a theory of knowledge, which should then be a constituent part of contemporary theories of interpretation. Therefore, unlike the recent trend in Philosophy of Law to limit interpretation to the theory of legal argumentation, we report that a broad theory of legal interpretation is not possible without a thought in advance about the process of understanding, like those offered by Heidegger and Gadamer. Similarly, it is also problematic to limit the discussion about the practice of interpretation to philosophical hermeneutics, as suggested Streck. If we are right, we can glimpse that the theories of legal argumentation and philosophical hermeneutics must be understood first in their complementarity than their differences.
\end{abstract}

Keywords: Interpretation, Legal argumentation, Philosophical hermeneutics, Theory of knowledge 


\section{INTRODUÇ̃̃̃O}

Ao discutir sobre a epistemologia jurídica ${ }^{1}$ e a prática dos juristas ${ }^{2}$, um jusfilósofo francês certa vez se perguntou: eles sabem do que estão falando ou falam sobre o que sabem? ${ }^{3}$ (ATIAS, 1994, p. 29, tradução livre). Não é claro se as chamadas teorias contemporâneas da argumentação jurídica respondem satisfatoriamente à pergunta de Christian Atias (1947-2015). Populares no meio jurídico, teorias como a de Robert Alexy oferecem caminhos interpretativos a que os juristas devem seguir em busca da melhor decisão possível, sobretudo para os casos difíceis (hard cases). A pergunta de Atias, entretanto, permanece sem resposta na teoria de Alexy, pois, ao passo que Alexy discute como deve ser a interpretação, Atias se questiona como se dá a interpretação e, especialmente, em como é possível a interpretação enquanto processo de conhecimento. ${ }^{4}$ A pergunta pode então ser traduzida em termos mais específicos: qual é o papel do conhecimento na construção da interpretação?

Uma pista para avançarmos na construção de respostas para as perguntas levantadas pode ser encontrada na seguinte constatação: não é possível compreender o Direito sem compreender a própria estrutura do acontecimento compreensivo (PEREIRA, p.176). O processo de compreensão do Direito, antes mesmo de ser, como querem alguns juristas, simplesmente interpretação jurídica, é fenômeno de compreensão e, como tal, implica invariavelmente a reflexão sobre as condições nas quais a intepretação se dá. Por isso, mesmo do ponto de vista lógico, uma teoria capaz de descrever as condições nas quais se dá a

\footnotetext{
1 O autor afirma em seu trabalho que "se há um conhecimento jurídico, não deve ser impossível conceber seu estudo epistemológico" (p. 11, tradução livre). Uma interpretação dessa passagem é oferecida por MELKEVIK ao esclarecer que o entendimento de ATIAS quanto a uma epistemologia jurídica aponta para uma suposta "especificidade do direito de mobilizar um conjunto de conhecimentos jurídicos registrados, históricos e práticos em uma infinidade de experiências jurídicas, de decisões judiciais, de disposições legais e regulamentares, bem como em formas de raciocínio e julgamentos apoiados pela profissão jurídica" (1995, p. 549, tradução livre). Ao discorrer sobre a existência da "epistemologia de um conhecimento jurídico", o autor se coloca numa posição defensora da relação sujeito-objeto, cunhada pela tradição filosófica, mais especificamente nas figuras de Aristóteles e Platão, representadas em seu trabalho pela relação entre os juristas e a lei.

${ }^{2} \mathrm{O}$ autor enfatiza, ainda, segundo MELKEVIK, que "a epistemologia jurídica não pode ser caracterizada sem se referir ao conhecimento jurídico como objeto científico, e aos detentores de conhecimento jurídico, ou seja, à comunidade jurídica como sujeito desse conhecimento" (1995, p. 550, tradução livre).

${ }^{3}$ Savent-ils de quoi ils parlent ou parlent-ils de ce qu'ils savent?

${ }^{4}$ Trata-se da oposição à tradição filosófica da abordagem do problema do conhecimento a partir da relação sujeito- objeto, superada a partir da "virada ontológica", promovida por Heidegger, quando apresenta sua reflexão sobre o "círculo hermenêutico". Autores como Gadamer, entre outros filósofos, passam a reconhecer na abordagem do problema do conhecimento que "toda compreensão emerge em favor de um contexto universal do qual somos já e sempre parte" (GRONDIN, 2003, p. 82) e, sendo assim, o acontecimento compreensivo mostrar-se-ia como uma questão de participação, de compartilhamento, tratando-se, portanto, de uma relação intersubjetiva: sujeito-sujeito.
} 
compreensão enquanto fenômeno é, em certa medida, uma condição de possibilidade para uma teoria que busca orientar a prática dessa. Nessa medida, o melhor ponto de partida para uma teoria da interpretação não pode ser, pois, a discussão sobre como a interpretação deve ser, mas como ela é. Isso não quer dizer, entretanto, que não há espaço para a argumentação jurídica, mas que é necessário um esforço anterior, mesmo que propedêutico, com o objetivo de construir uma teoria mais ampla sobre a compreensão, da qual a interpretação jurídica seja parte.

Se estivermos certos, será possível vislumbrar que, apesar da sua importância e contribuição para a reflexão e desenvolvimento da prática de tomada de decisões, as teorias da argumentação jurídica não são capazes de explicar satisfatoriamente o processo de compreensão, que é um ponto de partida para a interpretação e a argumentação jurídica. Observar-se-á, igualmente, que problemática similar é enfrentada, no que diz respeito à prática de tomada de decisões, quando se quer limitar sua discussão à hermenêutica filosófica, como sugerem alguns de seus defensores. Nesse sentido, uma filosofia da compreensão é relevante como uma propedêutica à interpretação jurídica, devendo, ainda, ser pensada em conjunto com as teorias da argumentação.

\section{OS JURISTAS SABEM DO QUE ESTÃO FALANDO?}

No famoso capítulo oitavo da sua Teoria Pura do Direito (1934), Hans Kelsen afirmou que a Ciência do Direito não podia conhecer propriamente todos os elementos da interpretação. Isso porque há sempre um elemento humano que é incognoscível e quanto mais geral é a norma, tanto mais ela está sujeita a várias interpretações. Não há, para Kelsen, uma resposta única e nem possibilidade de julgar se uma decisão é mais correta do que outra possível, sobretudo para os casos mais complexos. Nesse contexto, a Ciência do Direito é apenas capaz de fornecer as possibilidades interpretativas, mas o juiz do caso concreto, que é o interprete autêntico do ordenamento jurídico, pode inclusive decidir de forma diferente daquela preconcebida pelo cientista do direito. Empenhado em construir uma Ciência do Direito, Kelsen se esforçou para não fazer juízos de valor a respeito da prática jurídica, mas, o que não é pouco, descrevê-la em seus elementos mais essenciais. Por isso, é correto dizer que a ciência, para Kelsen, resume-se em uma atividade que tem como única função a de descrever uma determinada realidade que pode ser constatada pela experiência (MIRANDA AFONSO, p.204). 
O que é interessante em Kelsen é que ele acreditava que o juiz irá muitas vezes julgar segundo os seus próprios pontos de vista, segundo as suas mais profundas idiossincrasias e não há nada que o cientista do direito possa fazer a respeito, já que estabelecer parâmetros de interpretação para as normas equivale a fazer juízos de valor, dizer como o direito deve ser, e não o que ele é, o que é não é o papel do jurista. Essa ideia de Kelsen está embasada na tese do relativismo filosófico. Para Kelsen, não há nada que pode ser considerado certo ou errado de um ponto de vista absoluto, não há uma única moral, mas várias, assim como há várias diferentes concepções de justiça. Em suas palavras:

\begin{abstract}
De fato, muitas e muitas normas de justiça, muito diversas e em parte contraditórias entre si, são pressupostas como válidas. Um tratamento científico do problema da justiça deve partir destas normas de justiça e por conseguinte das representações ou conceitos que os homens, no presente e no passado, efetivamente se fazem e fizeram daquilo que eles chamam justo, que eles designam como justiça. A sua tarefa é analisar objetivamente as diversas normas que os homens consideram válidas quando valoram algo como justo (KELSEN, 1998, p.16).
\end{abstract}

Se não há uma única moral, então também não pode haver, na visão de Kelsen, um critério universal de correção para o Direito. É por isso que não há, para Kelsen, possibilidade de dizer que uma interpretação do Direito é melhor do que uma outra igualmente possível, pelo que não é possível uma teoria deontológica da interpretação. A popular visão de Kelsen sobre o Direito, que pode ser dita positivista, incomodou muito os juristas que acreditam na necessidade de conter o "poder discricionário" dos juízes. Nesse sentido é que a reflexão sobre a forma mais apropriada de judicial reasoning ${ }^{5}$ tornou-se a pedra de toque do direito contemporâneo. Nesse contexto, a teoria dos princípios ou teoria dos direitos fundamentais de Alexy, assim como outros autores ${ }^{6}$, vem sendo invocada constantemente pelas cortes brasileiras ${ }^{7}$ como ferramenta para a resolução de casos difíceis.

No primeiro parágrafo do seu livro Conceito e validade do direito, Alexy afirma que o principal problema na polêmica acerca do conceito de direito é a relação entre direito e moral. Apesar de uma discussão de mais de dois mil anos, duas posições fundamentais continuam se contrapondo: a positivista e a não-positivista (ALEXY, 2011a, p. 3).

\footnotetext{
5 Refere-se aqui como judicial reasoning o processo de interpretação através do qual um juiz chega à conclusão sobre o resultado mais apropriado na análise de um caso concreto, bem como para o processo de fundamentação orientado para a justificação escrita do cabimento de suas razões de decidir. Nesse sentido, judicial reasoning equivale ao que chamamos, em português, de argumentação jurídica. Lênio Streck se refere com ironia ao modo como, nos últimos anos, as teorias da argumentação jurídica tornaram-se "a pedra filosofal da interpretação" (sic). Cf.:

STRECK,

2012.
} 
Por um lado, como afirma Alexy, todos os não-positivistas defendem a tese da conexão, eles falam que existe uma conexão necessária entre validade legal ou correção legal por um lado, e méritos e deméritos morais ou correção e incorreção moral por outro (ALEXY, 2008b, p. 285, tradução livre). Entre outros, essa é a posição, como vimos, de Kelsen. Portanto, as teorias positivistas defendem a tese da separação entre direito e moral, enquanto as teorias não-positivistas defendem a tese da conexão. Isso significa que para os positivistas o conceito de direito deve ser determinado sem a inclusão de elementos morais, enquanto que, para os não-positivistas, o conceito de direito deve ser definido como que conectado a elementos morais.

Daí que Alexy conclui que resta aos positivistas considerar apenas dois elementos de definição do direito, quais sejam a legalidade conforme o ordenamento e a eficácia social. É nesse sentido que todas elas têm em comum o fato de considerarem que o que é direito depende exclusivamente do que é estabelecido e $\backslash$ ou eficaz e que uma correção quanto ao conteúdo, seja de que natureza for, não tem nenhuma importância (ALEXY, 2011a, p. 4). Por outro lado, os não-positivistas, por defenderem a tese da conexão, não defendem, todavia, a exclusão dos outros elementos que constituem o conceito de direito positivista, apesar de o conceito de direito deve ser definido de forma que, além dessas características que se orientam por fatos reais, inclua elementos morais (ALEXY, 2011a, p. 4-5). Por isso é que, de acordo com o nãopositivismo, o Direito consiste não em dois elementos mas em três (ALEXY, 2012, p.3,

\footnotetext{
${ }^{6}$ Por exemplo, também a teoria do direito como integridade, de Ronald Dworkin, tem sido lembrada pelos tribunais brasileiros. Destarte as objeções de Dworkin a Alexy, o papel desempenhado pelos juízes se mostra assecuratório do compromisso do direito com a ideia de correção (em Alexy: o 'mais correto possível'; em Dworkin: capaz de fornecer 'uma única resposta correta'). A aceitação por parte de ambos da tese da conexão necessária entre direito e moral, alicerce para a ideia de correção, é que abre espaço para a distinção entre regras e princípios. Em Alexy, princípios representam a ideia de correção moral do direito (correção de primeira ordem), enquanto regras sugerem a dimensão da legalidade autoritativa e da eficácia social do direito (correção de segunda ordem). Para o jurista alemão, os princípios morais são e devem ser utilizados pelos juízes, pois o direito tem conexão necessária com a moral. Um tanto diferente entende Dworkin, para o qual princípios morais integrariam a moldura do ordenamento jurídico quando utilizados, desde que fossem extraídos do próprio direito, da história jurídica (precedentes, costumes, etc.). Para o jurista norte-americano, a moral é extraída da história jurídico-autoritativa. O intérprete, que é quem interpreta o caso concreto, tem uma responsabilidade político-jurídica, que é a responsabilidade de coerência com as questões de princípio da ordem jurídica. Conferir: DWORKIN, 2002 e 2003.

${ }^{7}$ Embora a aplicação incorreta dessas teorias seja recorrente no Brasil. Ver: SAPUCAIA, 2012 e 2013.
} 
tradução livre). Além da legalidade conforme o ordenamento e da eficácia social, o conceito de direito não-positivista contém necessidade um elemento ideal, o qual é a própria moral. A defesa da tese da conexão entre Direito e moral, portanto, é o fator decisivo para a classificação de um pensador como não-positivista.

Esta classificação de Alexy, não obstante, busca evidenciar também as várias formas possíveis em que pode se dar a relação entre Direito e moral. Nesse sentido é que em artigo intitulado On the Concept and the Nature of Law ele classifica o positivismo em positivismo exclusivo e positivismo inclusivo, ao passo que, por seu turno, o não-positivismo é dividido em não-positivismo exclusivo, não-positivismo inclusivo e, finalmente, não-positivismo superinclusivo. O positivismo exclusivo defende que o direito está necessariamente desvinculado da moral quanto ao seu conceito. Este é o caso Joseph Raz. Para outros positivistas, os inclusivos, a moral não está nem necessariamente excluída do conceito de direito, e nem necessariamente incluída. O próprio direito positivo pode estabelecer a inclusão da moral. Dentre os positivistas inclusivos estão, por exemplo, Jules Coleman. Quanto ao nãopositivismo, a sua forma mais curiosa é o não-positivismo superinclusivo para quem existe um dever incondicional de submissão ao direito positivo tendo por base na própria moral. Está posição é defendida, para Alexy, por Tomás de Aquino e Kant. Uma posição imediatamente contrária a esta é a do não-positivismo exclusivo. Para eles, todo e qualquer defeito moral torna a norma inválida. Daí que o não-positivismo exclusivo é a forma mais forte do não-positivismo (ALEXY, 2012, p.5, tradução livre). Esta posição é defendida, por exemplo, por Deryck Beyleveld e Brownsword Roger.

É o não-positivismo inclusivo que irá atenuar a radicalidade dessas concepções anteriores. Segundo Alexy, esta forma de não-positivismo é centrada na fórmula de Radbruch, segundo a qual apenas normas extremamente injustas não são normas jurídicas. Esta é a concepção do próprio Alexy. Em suas próprias palavras:

\footnotetext{
“a única forma de não-positivismo que dá a adequada força para ambas, a real e a ideal dimensão, isto é, para ambos o princípio da segurança jurídica e o princípio da justiça é o não-positivismo inclusivo" (ALEXY, 2012, p. 6, tradução livre).
}

Para Alexy, portanto, o Direito tem uma conexão necessária com a moral. Para ele, essa é uma é uma característica necessária dos ordenamentos jurídicos complexos. Toda norma jurídica, assim como todo ordenamento jurídico como um todo necessariamente formula uma 
pretensão de correção ${ }^{8}$. A pretensão de correção é uma pretensão de a norma ou o ordenamento jurídico seja considerado justo. A conexão necessária entre Direito e moral em Alexy pode ser transposta em um fórmula, conhecida como a fórmula de Radbruch:: as normas de direito injustas perdem a sua juridicidade quando são extremamente injustas. Mas o que é “extremamente injustas"? A resposta de Alexy a essa pergunta é bastante complexa, mas pode ser resumida, em linhas gerais, na seguinte ideia: os direitos humanos ou fundamentais são o conteúdo dessa ideia de correção e de justiça. Do ponto de vista de Alexy, é preciso então responder como deve se dá a aplicação dos direitos humanos ou fundamentais na prática jurídica em consonância com a conexão entre Direito e moral.

A resposta de Alexy passa por uma nova forma de se conceber regras e princípios do Direito. Isso porque, por ser serem princípios, os direitos fundamentais são tomados como o cerne do ordenamento jurídico, sendo aplicados de uma maneira diferente das regras do Direito. Para Alexy, as regras são comandos que expressam um dever ser real ou definitivo. Sendo assim, são normas que comandam, proíbem ou permitem algo de forma definitiva e, sendo válidas, podem apenas ser cumpridas ou descumpridas. Já princípios são comandos que expressam um dever ser ideal ou prima facie, uma vez que, por desconhecerem suas possibilidades fáticas e jurídicas de cumprimento, comandam que algo seja realizado na melhor medida possível. Sendo assim, há para princípios a possibilidade de cumprimento em graus. A otimização deste cumprimento se dá através da ponderação, técnica amplamente debatida hodiernamente. É a ponderação que possibilita a determinação da medida comandada de cumprimento de um princípio em relação às exigências de um princípio a ele oposto.

\footnotetext{
${ }^{8}$ É preciso, entretanto, mostrar que a pretensão de correção evidencia um vínculo necessário entre direito e moral e que, portanto, o conceito de direito está ligado de forma necessária a ideia de moral. Nesse sentido, Alexy fornece dois exemplos: "o do primeiro artigo de uma nova constituição para o Estado X, onde a minoria oprime a maioria" (ALEXY, 2011, p. 43-44) e o exemplo em que um juiz profere a seguinte sentença carente de interpretação: "o réu é condenado à prisão perpétua, o que é incorreto" (ALEXY, 2011, p. 46). No primeiro exemplo, a minoria, apesar de querer gozar amplamente das vantagens da opressão da maioria, também pretende ser honesta, por isso proclama, como primeiro artigo da constituição, a seguinte norma: "X é uma república soberana, federal e injusta" (ALEXY, 2011, p. 44). Para Alexy, é evidente que este artigo possui um defeito, resta saber qual é ele. Segundo uma primeira interpretação possível, diríamos que se trata de um defeito técnico da norma, já que, expondo textualmente a injustiça da situação, restaria mais difícil o gozo das vantagens da opressão. No entanto, diz Alexy, na medida em que a norma também diz que o Estado é republicano, constata-se o mesmo defeito técnico em relação a obstaculizarão do gozo da minoria. Este novo elemento problematiza a interpretação segunda a qual se trata meramente de um defeito técnico, já que quanto à redação da "injustiça" parece haver um absurdo, enquanto que em relação ao "republicano" não (ALEXY, 2011, p. 44). Para Alexy, o problema evidenciado é um problema não de interpretação, mas um defeito conceitual. É que o ato de legislação constitucional está ligado a uma pretensão de correção, a qual, neste caso, toma a forma de uma pretensão de justiça. É nesse sentido que se pode dizer que ocorre uma contradição performativa no ato do legislador constitucional na medida em que o conteúdo do ato nega a sua pretensão mais fundamental que é
} 
As implicações desta distinção entre regras e princípios, para Alexy, dizem respeito a todas as áreas do direito e tem especial implicação em relação aos direitos fundamentais. Como quer Alexy, os direitos fundamentais são (ALEXY, 2014, p. 125-131): i) direitos de um grau mais elevado, pelo fato de estarem contidos na Constituição e, assim, ocuparem posição mais elevada na estrutura do ordenamento jurídico; ii) direitos dotados de maior força executória, uma vez que vinculam, como direito imediatamente válido, tanto a legislação, como os poderes executivo e judiciário, sendo ainda capazes de regularem as relações entre os cidadãos ao servirem como uma expressão de valores; iii) direitos que lidam com objetos de maior importância, haja vista que dizem respeito à elementos da estrutura fundamental da sociedade (ex. propriedade, liberdade de expressão, religião, etc.); iv) direitos que comportam uma maior medida de abertura, tendo em vista que aquilo que enunciam não se deixa extrair somente do texto seco, mas da interpretação que se dá a eles, o que possibilita que sua acepção se dê por um procedimento discursivo racional na prática dos tribunais constitucionais ${ }^{9}$.

A ideia de Alexy é que é possível, então, estabelecer critérios objetivos para o julgamento das decisões judiciais. Mais ainda: esses critérios poderiam orientar os juízos na busca da solução mais justa e democrática para o caso concreto. Não há dúvidas do potencial positivo desse tipo de contribuição para as práticas dos tribunais. Entretanto, é necessário se perguntar também se Alexy não peca ao confiar em demasia na capacidade ou mesmo possibilidade dos juízos em seguir os seus enunciados racionais. Talvez a prática do direito, como queria Kelsen, não possa de fato ser inteiramente racionalizada. Talvez exista um componente irresistível no momento do julgamento que escapa à racionalidade procedimental de Alexy e outros. Se essa suposição estiver correta, e tomado como óbvio que compreender todos os elementos implicados na interpretação jurídica é essencial na busca da melhor solução possível para cada caso, seria então prudente perguntar se existe tal teoria capaz de compreender com maior desenvoltura os processos mais complexos implicados na intepretação jurídica. Essa teoria ou filosofia seria não um substituto, mas uma importante ferramenta auxiliar à

\footnotetext{
${ }^{9}$ Essa visão interpretativista dos direitos fundamentais tem sofrido críticas que a acusam de não democrática, vez que resultaria na despolitização da discussão sobre o que são os princípios, transferindo-a para as cortes constitucionais. Fala-se em um atentado à representação democrática. Em resposta a esta objeção, Alexy faz uma distinção entre representação política e representação argumentativa do povo. Baseado nos elementos da teoria da justiça de John Rawls, Alexy sugere que a representação política é a competência atribuída aos legisladores em um sistema democrático e reflete o consenso dado entre os cidadãos acerca dos princípios de justiça a reger as instituições de base da sociedade, viabilizados pelas ideias de cooperação social, consenso sobreposto e razão pública. Já a representação argumentativa, resulta da competência dos tribunais para decidir casos concretos, mas, principalmente, de sua obrigação em fundamentar argumentativamente suas decisões, oferecendo ao público suas razões de decidir pautadas nos direitos fundamentais arraigados na Constituição, resultantes daquele consenso entre os cidadãos. Nesse caso, os tribunais estariam representando os cidadãos argumentativamente.
} 
argumentação jurídica, capaz de torná-la, na melhor das hipóteses, mais efetiva, mas, no pior cenário, pelo menos salvaguardá-la de cometer certos equívocos.

Ante ao panorama em destaque, instalou-se no ano de 2014 um debate entre teóricos do direito brasileiros a partir da atribuição de uma suposta problemática observada à teoria jurídica de Robert Alexy de não conter um necessário aporte filosófico. Tal afirmação, proferida pelos juristas André Karam Trindade e Lenio Luiz Streck, suscitou a instauração de um debate entre o que se chamou de "os defensores de Alexy" e os "defensores de Trindade e Streck" . Inicialmente, se apontava para a necessidade de reflexão do modo como a teoria do jurista alemão viria sendo aplicada no Brasil. No entanto, no curso da discussão, se observou um perfil que, para além deste questionamento, apontava para um embate entre a adoção de distintos “paradigmas" jurídico-filosóficos.

Ao passo que Trindade, Streck e seus defensores defendiam apenas se justificar um paradigma de matriz filosófica heidegger-, gadamer- e dworkiana, reafirmava-se a tese de Streck sobre a possibilidade, e para ele, necessária "superação enquanto negação" do positivismo pelo (neo)constitucionalismo pautado na hermenêutica filosófica. Por outro lado, na racionalidade da alegação de insuficiência da hermenêutica como teoria do direito apresentada por Alexy - reafirmados foram os argumentos deste autor para a defesa de um conceito não-positivista do direito enquanto superação do positivismo que, no entanto, o submete a crítica e incorpora seus avanços. Chega-se a atribuir a sua teoria discursiva do direito um caráter neo-positivista, que se verificaria em detrimento do (neo)constitucionalismo e seria reflexo de uma suposta "crise paradigmática do direito".

Ao que se observa, dada a dificuldade de se rejeitar a manutenção, em certa medida e especialmente no direito brasileiro, do direito positivo, constitui uma maioria os teóricos e aplicadores do direito que caminham em direção à tese da sua necessária superação que não implica, porém, em um total rompimento com suas contribuições, ao que poder-se-ia designar, juntamente com Alexy, não-positivismo. Sob esta ótica de "superação positiva", desenvolverse-ão, dentre outras, as teorias da argumentação, sobre as quais se promove o presente debate. Apresenta-se, porém, uma problemática à recepção das teorias da argumentação, uma vez fecundas sob essa ótica, quando confrontadas com a tese de uma necessária "superação enquanto negação". Essas duas diferentes acepções de um panorama pós-positivista - ora "positivo", ora "negativo" - alertam que, embora a recepção da racionalidade que as teorias da

${ }^{10}$ Conferir: STRECK e TRINDADE, 2014; OLIVEIRA e TRIVISONNO, 2014a e 2014b; OLIVEIRA e ROSA, 2014. 
argumentação abrigam pareça mais justificada, se faz necessário atentar para este outro panorama que se pretende "superador-negativo", observando-se os contornos da tese (neo)constitucionalista ao menos para melhor compreender o impasse inerente à discussão acerca do que chamamos pós-positivismo.

A discussão apontada não apenas acentua o grau de importância de uma reflexão que se volte à possibilidade de articulação da teoria da argumentação e da hermenêutica filosófica, como aponta para a necessidade de se refletir se o encerramento em um paradigma teórico, qualquer que seja ele, não recai em contradição com a própria natureza do direito enquanto ciência social aplicada e não como hard science, sendo este o local de pretensão por exatidão como sugere Thomas Kuhn, de quem origina a articulação da palavra paradigma enquanto modelo, ainda que transitório, de um método científico que tenha pretensão de exatidão; o que no direito não parece possível, dado que circunscreve o agir do agente racional, não de coisas, e que este agente, enquanto indivíduo, livre e situado entre iguais é um ser de possibilidades, o sendo o direito igualmente, não observando enquadramento em apenas um único paradigma.

\section{OS JURISTAS FALAM (APENAS) DO QUE SABEM?}

Este ano, no Texas (EUA), um jovem foi a julgamento porque agrediu o ex-namorado de sua namorada. Josten Bundy não poderia imaginar a sua sentença, proferida pelo juiz de direito Randall Rogers: ele deveria pedir a sua namorada em casamento em 30 dias ou seria condenado a ficar preso por 15 dias. Sem opção, os jovens se apressaram em casar ${ }^{11}$. Obviamente o caso é incomum, mas através dele se pode levantar a seguinte pergunta: o que diria Alexy a esse respeito? Sem dúvidas, Alexy afirmaria, com razão, que a decisão não é correta, pois não foi cumprido o dever de fundamentação racional. Entretanto, será que essa afirmação não empobrece a riqueza de elementos que compõem o caso? Será que a decisão não tem algo a ver, por exemplo, com aspectos mais complexos, como a inserção das partes e do juiz na cultura conservadora do Texas? E se tiver, será que não há uma filosofia mais atenta a forma como constituímos nossos juízos e preconceitos?

Uma forma de abordar a questão é aquela proposta por Hans Georg Gadamer (19002002), quando afirma que só o reconhecimento do caráter essencialmente preconceituoso de

${ }^{11}$ Ver: INDEPENDENT, 2015. 
toda compreensão pode levar o problema hermenêutico à sua real agudeza (GADAMER, 2013, p. 360). De fato, garantir uma compreensão correta é reconhecer que toda compreensão se funda sobre as pré-compreensões do intérprete, pois este deve necessariamente articular aquilo que o texto lhe diz com o que antecipadamente concebia, chegando a uma resultante que lhe possibilite que suas pré-compreensões não percebidas se revelem.

Em Verdade e Método (1960), Gadamer se propõe a tarefa de descrever as condições pelas quais a compreensão se dá. Ao contrário de Alexy, Gadamer não busca formular uma teoria capaz de orientar a prática interpretativa, mas descrevê-la enquanto fenômeno. Para tanto, remonta à descrição heideggeriana do círculo hermenêutico, a fim de aludir que a interpretação de um texto, embora inicie-se com as concepções prévias do intérprete, não pode ser imposta por estas; as concepções prévias deveriam ser, na medida em que o intérprete se aprofunda no sentido do texto, substituídas por concepções mais adequadas. Nesse sentido a compreensão se mostraria como uma constante reformulação do projeto inicial, que demanda o esforço de se voltar para "as coisas elas mesmas" (GADAMER, 2013, p. 355).

Igualmente, a importância dos preconceitos pode ser transposta à hermenêutica histórica. Gadamer (2013, p. 367-368) sustenta nesse sentido que:

\footnotetext{
(...) não é a história que nos pertence mas somos nós que pertencemos a ela. Muito antes de nos compreendermos na reflexão sobre o passado, já nos compreendemos naturalmente na família, na sociedade e no Estado em que vivemos. A lente da subjetividade é um espelho deformante. A autorreflexão do indivíduo não passa de uma luz tênue na corrente cerrada da vida histórica. Por isso, os preconceitos de um indivíduo, muito mais que seus juízos, constituem a realidade histórica de seu ser.
}

O autor defende, ainda, que deve se distinguir entre "preconceitos ilegítimos" e "preconceitos legítimos". Apenas estes últimos encontrariam espaço no trabalho hermenêutico, devido sua tênue relação com a tradição. Gadamer sustenta que a compreensão suporta a condição hermenêutica de pertencer à tradição. É da tentativa de conexão entre o que é transmitido e aquilo que a tradição cunhou como familiar que resulta a estranheza motivadora do trabalho hermenêutico. Gadamer (2013, p. 388), assim, apresenta a compreensão descrita como o jogo no qual se dá o intercâmbio entre o movimento da tradição e o movimento do intérprete. Assim, em toda compreensão, produz-se uma aplicação, de modo que aquele que compreende, está ele mesmo dentro do sentido do compreendido. Ele forma parte da mesma coisa que compreende (GADAMER, 1998, p. 19). Esta elucidação muito inspira a reflexão 
acerca da forma como juízes encontrariam as respostas para as questões postas a suas apreciações e auxilia na persecução de uma solução à questão que intitula este ensaio.

Compreender é sempre interpretar e a interpretação é a forma explícita da compreensão (GADAMER, 1999, p. 459), não se tratando de um ato posterior ou complementar. A compreensão se dá pela interpretação dos significados e a aplicação de seus sentidos ao presente histórico do intérprete. A compreensão, interpretação e aplicação integram o denominado processo hermenêutico, o que sustenta a ideia da circularidade hermenêutica. A partir da ideia de circularidade é possível observar a existência das finalidades práticas a que se destina a hermenêutica. No âmbito do Direito é a própria ideia de circularidade que possibilita a acepção da tese de que a hermenêutica figuraria como recurso de persecução da ratio decidendi em uma abordagem concreta como aquela promovida pelos juízes nos tribunais.

Gadamer irá relacionar, no que tange a discussão acerca das questões de justiça, a hermenêutica filosófica à ética aristotélica. Segundo Gadamer, há na aplicação do direito, na figura das leis, uma peculiaridade, uma vez que as leis são gerais e não podem conter em si mesmas a realidade prática em toda sua concreção. Este é o problema da hermenêutica jurídica. Por não abranger a realidade prática em toda sua concretude, a lei se mostraria sempre deficiente e não permitiria a aplicação simples da mesma (GADAMER, 1999, p. 473-474). Na aplicação destas seu caráter universal haveria de ser relacionado às dimensões particulares dos casos concretos, e sendo assim, ao intérprete caberia o compromisso com um saber ético. Este compromisso reporta ao conceito aristotélico de phronesis e insinua a demanda por um autoenvolvimento do intérprete com a situação a que aborda a partir de uma perspectiva, simultaneamente, individuada e orientada na auteridade, uma vez que se encontra vinculado a um âmbito prático e comunitário que deve servir de parâmetro para a aplicação da lei.

Acerca da hermenêutica jurídica Gadamer aduz:

\begin{abstract}
A hermenêutica jurídica recorda em si mesma o autêntico procedimento das ciências do espírito. Nela temos o modelo de relação entre passado e presente que estávamos procurando. Quando o juiz adequa a lei transmitida às necessidades do presente, quer certamente resolver uma tarefa prática. O que de modo algum quer dizer que sua interpretação da lei seja uma tradução arbitrária. Também em seu caso, compreender e interpretar significam conhecer e reconhecer um sentido vigente. O juiz procura corresponder à "ideia jurídica" da lei, intermediando-a com o presente. É evidente, ali, uma mediação jurídica. O que tenta reconhecer é o significado jurídico da lei, não o significado histórico de sua promulgação ou certos casos quaisquer de sua aplicação. Assim, não se comporta como historiador, mas se ocupa de sua própria história, que é seu próprio presente. Por consequência, pode, a cada momento, assumir a posição do historiador, face às questões que implicitamente já o ocupara, como juiz (1999, p. 493).
\end{abstract}


Gadamer atribui aos juízes a tarefa de complementar o direito na medida de sua função aplicadora, já que quando o jurista se sabe legitimado a realizar a complementação do direito, dentro da função judicial e face ao sentido original do texto legal, o que se faz é o que, seja como for, tem lugar em qualquer forma de compreensão (GADAMER, 1999, p. 504).

É importante destacar que a aceitabilidade dos preceitos hermenêuticos no que tange ao papel desempenhado pelos juízes, conforme exposto por Gadamer, é parcial na doutrina jurídica. Em geral, sua filosofia é vista como expressivamente elucidativa no que tange ao processo da compreensão. No entanto, no que se refere à prática judicial suas reflexões sofrem a crítica por parte de muitos estudiosos do direito de não promover uma distinção necessária entre discurso de justificação e de aplicação. Juristas como Jürgen Habermas e Klaus Günther, sugerem nesse sentido que, quando não promovida tal distinção, dar-se-ia ao intérprete um poder demasiadamente forte, quase legiferante.

Não cabe aqui adentrar ao tema da suposta atuação dos juízes como legisladores positivos, embora esta discussão se encontre em destaque no debate jurídico atual. $\mathrm{O}$ texto que aqui se pretendeu desenvolver situa-se antes na reflexão acerca do pano de fundo prático-teórico em que os juízes estão inseridos em sua prática diária de apreciações. Basta a indicação dos preceitos hermenêuticos para melhor visualizar na sociedade como a historicidade e as précompreensões repercutem na acepção e interpretação do direito e, em especial, dos direitos fundamentais. Exemplos de mutações de conceitos orientadas pela atualização dos valores na sociedade podem ser observados na jurisprudência de diversos sistemas jurídicos.

Para os hermeneutas convictos reside na prática judicial uma ligação indissociável com todo o processo de compreensão, interpretação e aplicação ora apresentado pela circularidade do processo hermenêutico. Para estes o círculo hermenêutico não é uma "opção metodológica", mas "um acontecimento que envolve a compreensão" (OLIVEIRA; ROSA, 2014, p. 7). Aos menos convictos importa significativamente o processo hermenêutico, mas deveria procurar conexão com a argumentação jurídica, para se tornar suficiente para se apresentar como método de interpretação jurídica, e mais especificamente, de decisão judicial. Nestes termos posicionase, como dito, Alexy, que através da proposta da ponderação como procedimento discursivamente racional busca o que entende ser um necessário aperfeiçoamento analítico ao círculo hermenêutico, uma vez compreender que a hermenêutica filosófica não se apresentaria como uma teoria do direito, embora uma adequada teoria descritiva da compreensão (OLIVEIRA; TRIVISONNO, 2014, p. 2). 
Desconsideradas essas divergências, o que deve ainda ser destacado é que entre estes teóricos existe outra importante aproximação (além da aceitação da importância do processo hermenêutico): em geral aderem à tese da conexão necessária entre direito e moral, e indagações acerca da necessidade ou dispensabilidade de tributação das decisões do direito à uma teoria moral são orientadoras do debate acerca do papel desempenhado pelos juízes em suas atuações enquanto magistrados. Diferentemente se configurarão as teses acerca da forma de aplicação do direito pelos juízes sob a ótica da tese da separação ou daqueles que embora não se vinculem a um ceticismo completo da possibilidade de acepção de formas morais no conceito de direito, criticam as concepções universalistas sobre o conteúdo dos conceitos morais. É o caso do jurista norte-americano Richard Posner. Ensina o professor Rafael Tomaz de Oliveira (2013, p. 4) que para Posner:

\begin{abstract}
(...) é possível ao investigador mapear certo conjunto de crenças e sentimentos que compõem a dimensão moral de uma determinada e específica comunidade de indivíduos. Mas, por outro lado, seria impossível universalizar o conteúdo conhecido dentro daquelas condições específicas de modo a aplicar suas normas em outro local, diferente daquele em que tais conteúdos tiveram origem. (...) no momento de decidir, mais importante do que o juiz conhecer tais conteúdos morais (por exemplo, qual o valor da democracia no seio de uma comunidade; o que significa a cláusula de igual respeito; ou se é compatível com a Constituição uma lei que proíbe o suicídio assistido por médicos), é ele ter o domínio instrumental das questões econômicas, políticas e sociais envolvidas na questão. É preciso que ele tenha um domínio, com máxima previsibilidade possível, sob as consequências geradas por sua decisão, tendo sempre como guia a adoção da medida que traga maior benefício ou uma melhora nas condições gerais observadas pelas pessoas envolvidas no caso.
\end{abstract}

Esse entendimento é apresentado por Posner em seu livro The Problematics of Moral and Legal Theory, o qual se apresenta como um manifesto pragmaticista no Direito. Atenta Tomaz de Oliveira que:

(...) afirma-se nele que os métodos de investigação e decisão do Direito não devem ser tributários de uma teoria moral "metafísica", mas, sim, devem ser buscados pragmaticamente, no seio das ciências sociais e do senso comum. (...) os juízes — ou qualquer outro tomador de decisões no âmbito do Direito - quando se vêem diante de casos que não encontram uma resposta simples a partir das fontes corriqueiras de orientação (Constituição, leis, precedentes), "nada podem fazer além de recorrer a noções derivadas da condução dos negócios públicos, dos valores profissionais e pessoais, da intuição e da opinião". Essa seria, segundo o autor, uma abordagem mais condizente com aquilo que efetivamente se passa no âmbito das práticas decisórias no Direito. Seria uma perspectiva mais profissional e menos teórica de aproximação do fenômeno jurídico. 
$\mathrm{O}$ ataque de Posner às concepções teóricas do direito, embora existam razões para se sustentar que a concepção de Posner também abriga uma teoreticidade ainda que não filosóficoreflexiva mas sociológico-descritiva, consiste em uma apresentação de uma nova e instigante forma de se visualizar as práticas decisórias e, igualmente, orienta para a necessidade de relacioná-la com a prática da efetiva abordagem de casos concretos.

Encaminhando-se para a conclusão deste breve ensaio, necessário esclarecer neste momento, que não se encontrará aqui a resposta para a questão que intitula o texto. Esta demanda uma análise da fidelidade das práticas decisórias com a teoria que se resolver adotar, possua ela uma matriz filosófica ou sociológica. O que se observa, a grosso modo, é que muitas facetas tomam as teorias do direito, mas o que parece menos se observar é a modulação das razões de decidir dos magistrados às teorias do direito, mas mais as modulações das teorias do direito às razões de quaisquer espécie que os magistrados queiram sustentar na decisão de um caso concreto. Esta realidade nos é recorrentemente exposta nos votos dos juízes, desembargadores e ministros das cortes judiciais em todo país. As controvérsias que se observa na execução dos procedimentos decisórios apontam para a necessidade de melhor observá-los.

\section{CONCLUSÃO}

É inegável a relevância das teorias da argumentação jurídica, sobretudo a de Alexy, para a intepretação e aplicação do direito na contemporaneidade. Apesar disso, entretanto, as teorias da argumentação jurídica também estão sujeitas a limitações. Essas limitações, entretanto, não é um argumento razoável para a negação dessas teorias, apesar de alguns autores defenderem, a nosso ver, erroneamente, essa tese. Seja como for, algumas dessas limitações podem ser ao menos parcialmente superadas, ou melhor elucidadas, se levarmos em conta as contribuições de outros projetos filosóficos contemporâneos. Um deles é o da hermenêutica filosófica, sobretudo como elaborada por Gadamer, que propõe uma análise mais detida sobre o processo da compreensão, do qual a intepretação jurídica é parte. Não é possível compreender o Direito sem entendê-lo como uma criação humana, historicamente datado e, assim como todo caso jurídico, e imerso em uma cultura, cheia de pré-concepções e referenciais simbólicos específicos. Nessa medida, vale o ímpeto de pensar a argumentação jurídica e a hermenêutica filosófica como ferramentas complementares, que, apesar de não serem capazes de dar, se 
tomadas isoladamente, uma solução abrangente e razoável para os casos difíceis, podem juntas oferecer melhores resultados. Em verdade, é possível que nem mesmo se usadas em conjunto, como propomos, essas teorias serão capazes de compreender a interpretação jurídica em toda a sua complexidade. Mas mesmo nesse caso, seria possível dizer que ao menos vislumbramos, como quer Alexy, a melhor solução possível. 


\section{REFERÊNCIAS}

ALEXY, Robert. Conceito e validade do direito. São Paulo: Martins Fontes, 2011a.

ALEXY, Robert. Law, Morality, and the Existence of Human Rights. Ratio Juris. Vol. 25. N. 1, 2012, p. 2-14.

ALEXY, Robert. On the Concept and the Nature of Law. Ratio Juris. v. 21. n. 3, 2008a, p. 281299.

ALEXY, Robert. Teoria da argumentação jurídica: A Teoria do Discurso Racional como Teoria da Fundamentação Jurídica. Trad. Zilda Hutchinson Schild Silva. 3. ed., Rio de Janeiro, Forense, 2011b.

ALEXY, Robert. Teoria dos direitos fundamentais. Trad. Virgílio Afonso da Silva. São Paulo, Malheiros Editores, 2008b.

ALEXY, Robert. Teoria discursiva do direito. Trad. Alexandre Travessoni Gomes Trivisonno. 1. ed. Rio de Janeiro: Forense Universitária, 2014.

ATIAS, Christian. Épistémologie du droit. Coll. Que sais-je?, $\mathrm{n}^{\circ}$ 2840, Paris, Presses Universitaires de France, 1994.

DWORKIN, Ronald. Levando os direitos a sério. Trad. Nelson Boeira. São Paulo, Martins Fontes, 2002.

DWORKIN, Ronald. O império do direito. Trad. Jefferson Luiz Camargo. São Paulo, Martins Fontes, 2003.

GADAMER, Hans Georg. Verdade e Método: traços fundamentais de uma hermenêutica filosófica. Trad. Flávio Paulo Meurer. 13. ed. Petrópolis: Vozes, 2013.

GADAMER, Hans Georg. Trad. Flávio Paulo Meurer. 3. ed. Petrópolis: Editora Vozes, 1999.

GADAMER, Hans Georg. Trad. Flávio Paulo Meurer. 2. ed. Petrópolis: Editora Vozes, 1998.

HEIDEGGER, Martin. Carta sobre o Humanismo. Rio de janeiro: Biblioteca Tempo Universitário 5, 1967.

HEIDEGGER, Martin. O que é isto: a filosofia? Em: Conferências e escritos filosóficos. Trad. Ernildo Stein. São Paulo: Abril Cultural, 1979.

HEIDEGGER, Martin. Ser e Tempo. Trad. Marcia Sá Cavalcante Schuback. 15. ed. Petrópolis: Editora Vozes, 2005.

HEIDEGGER, Martin. Sobre a essência da verdade. Em: Conferências e escritos filosóficos. Trad. Ernildo Stein. São Paulo: Abril Cultural, 1979. 
INDEPENDENT. Texas judge orders defendant to marry girlfriend in 30 days - or go to jail. 09 agosto 2015. Disponível em: http://www.independent.co.uk/news/world/americas/texasjudge-orders-defendant-josten-bundy-to-marry-girlfriend-in-30-days-10447316.html.

KELSEN, Hans. O problema da Justiça. Trad. de João Baptista Machado. $3^{\text {a }}$ edição. São Paulo: Martins Fontes, 1998.

KELSEN, Hans. Teoria pura do Direito. $4^{\circ}$ edição. Trad. de João Baptista Machado. Coimbra: Armênio Amado Editor, 1976.

MELKEVIK, Bjarne. Chonique bibliographique sur Christian Atias "Épistémologie du droit" (1994). Em: Les Cahiers de droit, vol. 36, nº 2, 1995, p. 549-551.

MIRANDA AFONSO, Elza Maria. O positivismo na epistemologia jurídica de Hans Kelsen. Belo Horizonte: Faculdade de Direito da Universidade Federal de Minas Gerais, 1984.

OLIVEIRA, Júlio Aguiar de; TRIVISONNO, Alexandre Travessoni Gomes. Trindade e Streck, seus defensores e a filosofia. Consultor Jurídico. 26 abril 2014. Acessível em: <http://www.conjur.com.br/2014-abr-26/trindade-streck-defensores-filosofia-logicaornamental?> Acesso em: 28 abril 2014b.

OLIVEIRA, Júlio Aguiar de; TRIVISONNO, Alexandre Travessoni Gomes. Uma teoria do direito sem filosofia?! Crítica às objeções de Trindade e Streck à teoria de Alexy. Os Constitucionalistas. 15 abril 2014a. Acessível em:

$<$ http://www.osconstitucionalistas.com.br/uma-teoria-do-direito-sem-filosofia-critica-asobjecoes-de-trindade-e-streck-a-teoria-de-alexy> Acesso em: 16 abril 2014.

OLIVEIRA, Rafael Tomaz de; ROSA, Alexandre Morais da. Alexy, seus defensores e a filosofia como lógica ornamental. Consultor Jurídico. 19 abril 2014. Acessível em: <http://www.conjur.com.br/2014-abr-19/alexy-defensores-filosofia-logica-ornamental> Acesso em: 26 abril 2014.

OLIVEIRA, Rafael Tomaz de. Um debate sobre o lugar da Teoria do Direito. Consultor Jurídico. 12 jan. 2014. Acessível em: <http://www.conjur.com.br/2013-jan-12/diario-classedebate-lugar-teoria-direito?> Acesso em: 3 jun. 2014.

PEREIRA, Rodolfo Viana. Hermenêutica filosófica e constitucional. Belo Horizonte: Del Rey, 2006.

SAPUCAIA, Rafael Vieira Figueiredo. A aplicação da máxima da proporcionalidade no STF: um caso. Revista SJRJ, Vol. 20, N. 36, 2013, p. 193-204.

SAPUCAIA, Rafael Vieira Figueiredo. A derrotabilidade dos princípios e o Supremo Tribunal Federal. Observatório da Jurisdição Constitucional, Vol. 2, 2012, p. 1-15.

STRECK, Lenio Luiz. A Katchanga e o bullying interpretativo no Brasil. Consultor Jurídico. 28 junho 2012. Acessível em: <http://www.conjur.com.br/2012-jun-28/senso-incomumkatchanga-bullying-interpretativo-brasil> Acesso em: 19 agosto 2015. 
STRECK, Lenio Luiz; TRINDADE, André Karam. Alexy e os problemas de uma teoria jurídica sem filosofia. Consultor Jurídico. 05 abril 2014. Acessível em: <http://www.conjur.com.br/2014-abr-05/diario-classe-alexy-problemas-teoria-juridicafilosofia?> Acesso em: 07 abril 2014. 